\title{
Protección universal del derecho a la igualdad
}

\section{Universal protection of the right to equality}

\author{
José FERnANDo Lousada ARochena \\ Magistrado especialista de lo social - TSJ/Galicia \\ Doctor en Derecho / Graduado Social \\ Profesor asociado de Derecho Procesal Universidad \\ de A Coruña
}

ORCID: 0000-0002-4629-0539

Resumen. El derecho a la igualdad de los seres humanos y la prohibición de discriminación reconocidos en los instrumentos internacionales de derechos humanos exigen mecanismos efectivos de tutela. El estudio analiza los organismos y los procedimientos instaurados a nivel universal bajo el mandato genérico de Naciones Unidas y en el Sistema de Tratados. En particular, el estudio se detiene en el procedimiento de denuncias individuales en la Convención sobre la eliminación de todas las formas de discriminación contra la mujer (1979), la Convención sobre la eliminación de todas las formas de discriminación racial (1965), y la Convención sobre los derechos de las personas con discapacidad (2006). Finalmente, se analiza la eficacia interna de los dictámenes del Comité sobre la eliminación de todas las formas de discriminación contra la mujer.

Palabras clave: igualdad y no discriminación, tratados universales de derechos humanos, eficacia interna de las decisiones del CEDAW.

Abstract. The right to equality of human beings and the prohibition of discrimination recognized in international human rights treatys require effective guardianship mechanisms. The study analyzes the organizations and procedures established at the universal level under the generic mandate of the United Nations and in the Core international human rights instruments. In particular, the study focus in the procedure complaints from individuals in the Convention on the Elimination of All Forms of Discrimination against Women (1979), the Convention on the Elimination of All Forms of Racial Discrimination (1965), and the Convention on the Rights of Persons with Disabilities (2006). Finally, the effectiveness in Spain of the Committee's views on the elimination of all forms of discrimination against women is analyzed too.

Keywords: equality and non-discrimination, universal human rights treaties, effectiveness of CEDAW's views in Spain. 


\section{La igualdad en los instrumentos de derechos humanos emanados de la organi- zación de naciones unidas}

La igualdad de los seres humanos y la prohibición de discriminación están en la esencia de la totalidad de los textos internacionales de derechos humanos nacidos en el seno de las Naciones Unidas (NNUU). Baste recordar, a los efectos de contextualizar debidamente el entorno jurídico del objeto del estudio, algunas normas emblemáticas ${ }^{1}$.

La más emblemática es, sin duda alguna, el mismo artículo 1 de la Declaración Universal de Derechos Humanos de 1948 (DUDH): "todos los seres humanos nacen libres e iguales en dignidad y derechos". Resulta oportuno ahora recordar a Eleanor Roosevelt y Hansa Mehta -que representaban a los Estados Unidos de América y a la India, respectivamente, en la Comisión de Derechos Humanos de las Naciones Unidas, de la que la primera era Presidenta-, pues fueron las que se empeñaron en cambiar el artículo 1 de la DUDH, que en el proyecto decía "todos los hombres nacen iguales", para que pasara a decir lo que dice: "todos los seres humanos nacen libres e iguales".

Además, la DUDH establece en su artículo 2 que "toda persona tiene todos los derechos y libertades proclamados en esta Declaración, sin distinción alguna de raza, color, sexo, idioma, religión, opinión política o de cualquier otra índole, origen nacional o social, posición económica, nacimiento o cualquier otra condición". Y en su artículo 7 que "todos son iguales ante la ley y tienen, sin distinción, derecho a igual protección de la ley", así como "derecho a igual protección contra toda discriminación que infrinja esta Declaración y contra toda provocación a tal discriminación".

Siguen este concepto relacional de discriminación como prohibición de distinción en el ejercicio de los derechos reconocidos que se deriva de los artículos 1, 2 y 7 de la DUDH, el Pacto Internacional de Derechos Civiles y Políticos de 1966 (PIDCP), artículos 2.1 -referido a toda causa de distinción ${ }^{2}$ - y 3 -referido al sexo ${ }^{3}-$, y el Pacto Internacional de Derechos Económicos, Sociales y Culturales de 1966 (PIDESC), artículos 2.2 -referido a toda causa de discriminación ${ }^{4}$ - y 3 -referido al sexo ${ }^{5}$-. Aunque en el artículo 26 del PIDCP se aprecia un atisbo de superación de dicho concepto relacional de discriminación cuando

\footnotetext{
${ }^{1}$ Sobre la evolución del concepto de igualdad y no discriminación en los textos internacionales de derechos humanos hasta la fecha de su publicación, véase Miguel RODRÍGUEZ-PIÑERO / María Fernanda FERNÁNDEZ LÓPEZ, Igualdad y discriminación, Editorial Tecnos (Madrid, 1986). Un análisis más actualizado de la evolución del concepto de igualdad y no discriminación, aunque limitado a la igualdad de género, en José Fernando LOUSADA AROCHENA, El derecho fundamental a la igualdad efectiva de mujeres y hombres, Editorial Tirant lo Blanch (Valencia, 2014). También véase Encarnación CARMONA CUENCA (ed.), La perspectiva de género los Sistemas Europeo e Interamericano de Derechos Humanos, Centro de Estudios Políticos y Constitucionales (Madrid, 2015).

${ }^{2}$ Cada uno de los Estados Partes en el presente Pacto se compromete a respetar y a garantizar a todos los individuos que se encuentren en su territorio y estén sujetos a su jurisdicción los derechos reconocidos en el presente Pacto, sin distinción alguna de raza, color, sexo, idioma, religión, opinión política o de otra índole, origen nacional o social, posición económica, nacimiento o cualquier otra condición social.

${ }^{3}$ Los Estados Partes en el presente Pacto se comprometen a garantizar a hombres y mujeres la igualdad en el goce de todos los derechos civiles y políticos enunciados en el presente Pacto.

${ }^{4}$ Los Estados Partes en el presente Pacto se comprometen a garantizar el ejercicio de los derechos que se enuncian, sin discriminación alguna por motivos de raza, color, sexo, idioma, religión, opinión política o de otra índole, origen nacional o social, posición económica, nacimiento o cualquier otra condición social.

${ }^{5}$ Los Estados Partes en el presente Pacto se comprometen a asegurar a los hombres y a las mujeres igual título a gozar de todos los derechos económicos, sociales y culturales enunciados en el presente Pacto.
} 
establece que "la ley prohibirá toda discriminación", esto es no solo en el ejercicio de los derechos reconocidos en el PIDCP, y, en consecuencia, que la ley "garantizará a todas las personas protección igual y efectiva contra cualquier discriminación por motivos de raza, color, sexo, idioma, religión, opiniones políticas o de cualquier índole, origen nacional o social, posición económica, nacimiento o cualquier otra condición social”."

Además de estos textos generales en los cuales la igualdad y no discriminación se proyectan sobre los derechos en ellos reconocidos, se ha aprobado tres textos especiales garantes de concretas causas de igualdad y no discriminación en todos los ámbitos: la Convención sobre la eliminación de todas las formas de discriminación racial (1965); la Convención sobre la eliminación de todas las formas de discriminación contra la mujer (1979); y la Convención sobre los derechos de las personas con discapacidad (2006). Bajo esta diferente perspectiva, de un lado, al ser monográficos de una causa de discriminación, potencian su eficacia, y de otro lado, al proyectarse sobre todos los ámbitos, superan definitivamente la limitación derivada del carácter relacional de la discriminación que aparecía en la DUDH y en otros instrumentos internacionales. También es otro aspecto destacable la tendencia a considerar la igualdad como generadora de derechos en positivo, y no como una simple prohibición de distinción en negativo - una tendencia que se observa en la misma denominación de la Convención sobre los derechos de las personas con discapacidad, y que también se podría rastrear en la aplicación e interpretación de las disposiciones de los otros dos convenios citados-.

En definitiva, la igualdad y la no discriminación se encuentran claramente asentadas en el catálogo universal de derechos humanos. Pero -como ocurre con todos los demás derechos humanos- corren el riesgo de convertirse en ideas más o menos románticas, y en retórica vacía, si no van unidas a mecanismos serios de efectividad. A su análisis se dedica este estudio. Primero, se analizarán más genéricamente los mecanismos de protección que la igualdad comparte con el resto de los derechos humanos. Segundo, se analizará más específicamente el mecanismo de denuncias individuales instaurado en los tratados sobre motivos concretos de discriminación: la Convención sobre la eliminación de todas las formas de discriminación racial (1965); la Convención sobre la eliminación de todas las formas de discriminación contra la mujer (1979) -en cuyo análisis nos detendremos en especial-; y la Convención sobre los derechos de las personas con discapacidad (2006). Finalmente, se analiza la eficacia interna de los dictámenes del Comité sobre la eliminación de todas las formas de discriminación contra la mujer, pues es una cuestión que ha recibido una respuesta en nuestra jurisprudencia virtualmente extensible a los dictámenes de los demás Comités.

\section{Los mecanismos de protección que la igualdad comparte con el resto de derechos humanos}

Si bien la DUDH enumera los más importantes derechos civiles, políticos, económicos, sociales y culturales del ser humano, la DUDH no es más que una afirmación de buenas

\footnotetext{
${ }^{6}$ Miguel RODRÍGUEZ-PIÑERO / María Fernanda FERNÁNDEZ LÓPEZ, Igualdad ..., obra citada, pág. 94.
} 
intenciones emitida voluntariamente por los Estados miembros de Naciones Unidas, sin que obligara a estos jurídicamente y sin que tuviera carácter vinculante, pues no instaura ningún cauce de reclamación de los sujetos particulares ante instancias internacionales, ni establece ningún otro mecanismo jurídico acerca del control de efectividad por dichos Estados. Pero esto ha cambiado en el convencimiento de la necesidad de una tutela eficaz de los derechos humanos reconocidos, pudiéndose afirmar que, en la actualidad, la tendencia predominante en la doctrina científica y en la agenda política es favorable a dotar a los derechos de sus correspondientes garantías. El cambio en la concepción inicial a su actual sentido se ha calificado como una de "las más notables revoluciones en la historia de la sociedad y de las ideas contemporáneas"7.

Actualmente, están instaurados dos sistemas de protección universal de los derechos humanos -en los cuales están incluidos la igualdad y no discriminación-8:

1. Un sistema de protección se deriva del mandato atribuido a los órganos internos de las Naciones Unidas, lo que ha dado lugar al denominado como Sistema Universal, Institucional o Extraconvencional de Protección de Derechos Humanos.

2. Otro sistema de protección se deriva de la ratificación por los Estados Parte de tratados internacionales bajo el auspicio de Naciones Unidas, lo que ha dado lugar al denominado como Sistema de Tratados de Derechos Humanos de las Naciones Unidas.

2.1. La protección de la igualdad dentro del sistema universal de protección de derechos humanos

El Sistema Universal, Institucional o Extraconvencional de Protección de Derechos Humanos lo constituyen las medidas puestas en práctica por los propios órganos principales o subsidiarios en que se estructura la Organización de Nacionales Unidas con fundamento en los poderes en materia de derechos humanos que les confiere la Carta de las Naciones Unidas y en el deber general de cooperación de los Estados Partes. Más concretamente, el apoyo jurídico para estas competencias en materia de derechos humanos se encuentran en diversas disposiciones de la Carta de las Naciones Unidas: con carácter general, artículo 1.3 (al incluir entre los propósitos de las NNUU, el desarrollo y estímulo del respeto a los derechos humanos y a las libertades fundamentales de todos, sin hacer distinción por motivos de raza, sexo, idioma o religión), artículo 55.c) (que dispone que la ONU promoverá el respeto universal a los derechos humanos y a las libertades fundamen-

\footnotetext{
${ }^{7}$ Renata BREGAGLIO LAZARTE, “Sistema universal de protección de derechos humanos”, en Protección multinivel de derechos humanos (coords.: George Rodrigo BANDEIRA GALINDO / René URUEÑA / Aida TORRES PÉREZ), Red Derechos Humanos y Educación Superior (2013), pág. 93.

${ }^{8}$ Para profundizar en los distintos mecanismos de protección, y en particular para conocer su correcta utilización por personas particulares, es indispensable acudir a la página web de Naciones Unidas (www.un.org/es), y, en particular a la página web del Alto Comisionado de Naciones Unidas para los Derechos Humanos (www.ohchr.org/sp), así como a las pestañas referidas a las distintas Convenciones.
} 
tales de todos, sin hacer distinción por motivos de raza, sexo, idioma o religión, y la efectividad de tales derechos y libertades), y artículo 56 (que dispone que todos los Miembros se comprometen a tomar medidas conjunta o separadamente, en cooperación con la ONU, para la realización de sus propósitos); en particular, en relación con la Asamblea General, artículo 13.1.b) (que dispone que la Asamblea promoverá estudios y hará recomendaciones con la finalidad de ayudar a hacer efectivos los derechos humanos y las libertades fundamentales de todos, sin hacer distinción por motivos de raza, sexo, idioma o religión); y en relación con el Consejo Económico y Social, artículo 62.2 (al incluir entre las funciones y poderes del Consejo, la de hacer recomendaciones con el objeto de promover el respeto a los derechos humanos y a las libertades fundamentales de todos, y la efectividad de tales derechos y libertades), y artículo 68 (que atribuye al Consejo Económico y Social la potestad de establecer comisiones para la promoción de los derechos humanos).

Dada esta fundamentación en la Carta de Naciones Unidas se deriva que las competencias en materia de derechos humanos asumidas por sus propios órganos principales o subsidiarios es independiente de la aprobación de los Estados Partes, y que estos están además obligados por su deber de cooperación con la ONU. Como no se sustentan en convenios aprobados por los Estados miembros, sino en la labor institucional basada en el mandato de NNUU, a este sistema se le llama institucional o extraconvencional ${ }^{9}$. También se le denomina sin más universal, pues se aplica a la totalidad de los Estados Partes, hayan ratificado, o no, convenios de derechos humanos.

El Sistema Universal, Institucional o Extraconvencional de Protección de Derechos Humanos se ha ido reforzando progresivamente. Un hito significativo en ese proceso de fortalecimiento lo ha representado la Conferencia de Derechos Humanos celebrada en Viena, 1993, que, entre otras propuestas luego desarrolladas, condujo a la creación de un Alto Comisionado de las Naciones Unidas para los Derechos Humanos.

Ocupa, en fin, este sistema un lugar de primera línea en la vigilancia de las normas universales de derechos humanos, en él recayó la tarea de afrontar muchas de las peores violaciones registradas en las situaciones más críticas y tiene como objetivo central la mejora de la eficacia de las normas internacionales de derechos humanos ${ }^{10}$.

\subsection{1. Órganos de naciones unidas con competencias de derechos humanos}

Todos los órganos principales de NNUU ostentan, dentro del mandato de NNUU, competencias en materia de promoción y defensa de derechos humanos, tanto los órganos principales como los órganos subsidiarios. Recordemos que los órganos principales son: la Asamblea General; el Consejo de Seguridad; el Consejo Económico y Social (ECO-

\footnotetext{
${ }^{9}$ Denominación la segunda utilizada por Alexandre VIDIGAL DE OLIVEIRA, Protección Internacional de los Derechos Humanos - Justificaciones técnico-jurídicas para la creación de un Tribunal Mundial de Derechos Humanos (2011), tesis doctoral inédita accesible en el repositorio de la Universidad Carlos III de Madrid (enlace: https://e-archivo.uc3m.es/ handle/10016/13300, consultado a 24/02/2020).

${ }^{10}$ En este sentido, Alexandre VIDIGAL DE OLIVEIRA, Protección ... , op. cit., págs. 54 y 55.
} 
SOC); el Consejo de Administración Fiduciaria (sin actividad); la Corte Internacional de Justicia (CIJ); y la Secretaría (Carta de Naciones Unidas, artículo 7.1.).

Dentro de los órganos subsidiarios que se pueden establecer si fuere necesario (Carta de Naciones Unidas, artículo 7.2), debemos citar los siguientes: el Consejo de Derechos Humanos (subsidiario de la Asamblea General), la Comisión de la Condición Jurídica y Social de la Mujer (subsidiaria del ECOSOC), y el Alto Comisionado de las Naciones Unidas para los Derechos Humanos (ACNUDH, subsidiario de la Secretaría).

El Consejo de Derechos Humanos es el principal órgano para la promoción y defensa de derechos humanos, subsidiario de la Asamblea General e integrado por 47 miembros elegidos de forma directa e individual en votación secreta por mayoría en la Asamblea General. Fue creado en 2006 para superar las dificultades y rémoras que mermaban la eficacia de la anterior Comisión de Derechos Humanos, subsidiaria del ECOSOC e integrada por representantes políticos de los Estados miembros (precisamente esta composición era la causa de las dificultades y rémoras que sufría ${ }^{11}$ ).

En el ámbito competencial del ECOSOC, se creó en 1946 la Comisión de la Condición Jurídica y Social de la Mujer, que es el más destacado órgano intergubernamental para promover igualdad de género y empoderamiento de la mujer.

Integrado en la estructura de la Secretaría, se designa, desde 1993, un Alto Comisionado de las Naciones Unidas para los Derechos Humanos (ACNUDH) ${ }^{12}$ : su actuación se encuentra bajo la autoridad y dirección del Secretario General; su categoría es Secretario General Adjunto de Naciones Unidas; es el más alto funcionario con responsabilidad en la materia de los derechos humanos; y tiene a su cargo una Oficina.

\subsubsection{Procedimientos extraconvencionales de protección de los derechos humanos}

Tanto los órganos principales como los órganos subsidiarios ejercitan sus competencias en materia de promoción y defensa de derechos humanos a través de determinados procedimientos que se pueden clasificar en dos grandes grupos: procedimientos no contenciosos -que se tramitan sin mediar queja o denuncia alguna-, y procedimientos cuasicontenciosos -en los que media una queja o denuncia pero que se tramitan sin las exigencias de un procedimiento judicial contradictorio-.

Dentro de los procedimientos no contenciosos, los más habituales son los procedimientos de informes periódicos de los Estados miembros de las NNUU. El más ambicioso

\footnotetext{
${ }^{11}$ Kofi Annan propuso su creación en 2005 al entender que la Comisión de Derechos Humanos había venido experimentado una gran disminución de su credibilidad y profesionalismo debido al alto grado de politización y selectividad en sus trabajos (selectividad advertida especialmente en la elección de los países sometidos a procedimientos públicos especiales), y al hecho de que en algunos períodos hayan formado parte de la misma países acusados de violaciones graves y masivas de los derechos humanos (que han tendido a utilizar su condición de miembros de la Comisión para evitar ser condenados por sus violaciones de los derechos humanos o para criticar a otros países). Sobre este cambio, ver Natalia OCHOA RUIZ / Esther SALAMANCA AGUADO, "El Consejo de Derechos Humanos de las Naciones Unidas: un análisis preliminar", Revista Electrónica de Estudios Internacionales, núm. 12, 2006.

${ }^{12}$ Su creación es "el hito más importante en esta materia acontecido en los últimos años" (Yolanda GÓMEZ SÁNCHEZ, Constitucionalismo multinivel - Derechos fundamentales, UNED, 2015, pág. 127).
} 
es el Examen Periódico Universal que debe realizar el Consejo de Derechos Humanos sobre el cumplimiento por cada Estado de sus obligaciones respecto a derechos humanos bajo las siguientes premisas: se basa en información objetiva y fidedigna; se garantiza la universalidad del examen y la igualdad de trato respecto de todos los Estados; es un mecanismo cooperativo, basado en un diálogo interactivo, con la participación plena del país de que se trate y teniendo en consideración sus necesidades de fomento de la capacidad; este mecanismo complementa y no pretende duplicar la labor de los órganos creados en virtud de los tratados de derechos humanos.

Dentro de los procedimientos cuasicontenciosos, se deben encuadrar los procedimientos 1235 y 1503 instaurados por el ECOSOC para la extinta Comisión de Derechos Humanos, y que se mantienen con el vigente Consejo de Derechos Humanos.

El Procedimiento de la Resolución no 1235 (XLII) del ECOSOC para tratar situaciones de violación masiva y flagrante de derechos humanos relacionadas con situaciones de apartheid, discriminación racial y dominación colonial, fue instaurado en 1967 en relación con las denuncias de apartheid en Rhodesia y Sudáfrica, y ampliado en 1975 para las denuncias derivadas de la situación de los derechos humanos en Chile, aunque actualmente su utilización se admite en relación con toda situación de violencia persistente con violación de derechos humanos, sea la violación global o sea individual.

Merced a este procedimiento se ha instaurado un tupido Subsistema de Relatores Especiales de Derechos Humanos. Y es que los mandatos conferidos al amparo de este procedimiento se encargan a relatores especiales, expertos independientes o grupos de trabajo, pudiendo ser geográficos (en relación con un país) o temáticos (algunos ejemplos: el Grupo de Trabajo sobre Desapariciones Forzadas o Involuntarias; o sobre la Detención Arbitraria; el Relator Especial sobre las Ejecuciones Extrajudiciales, Sumarias o Arbitrarias; sobre la Tortura; sobre la Independencia de Magistrados y Abogados; o sobre las Formas Contemporáneas de Esclavitud). En todo caso, son mandatos de carácter temporal (inicialmente de un año, aunque la renovación de los mandatos temáticos se suele espaciar más tiempo, usualmente se hace cada tres años).

Se inicia el procedimiento con base en comunicaciones recibidas de diversas fuentes (las víctimas o sus familiares, organizaciones locales o internacionales, etc.). La admisibilidad de las comunicaciones no está sometida a reglas formales estrictas, ni tampoco se establece la necesidad de agotamiento de los recursos judiciales internos.

Se trata de un procedimiento público. Cabe incluso la realización de visitas in situ, con entrevistas a las víctimas y los testigos, o enviar acciones urgentes de carácter humanitario. No obstante, para que estas visitas se lleven a cabo es necesario contar con una invitación por parte del gobierno interesado. Una vez cursada la invitación, las autoridades nacionales deben facilitar las medidas para que la visita pueda realizarse.

Se establece también la posibilidad de medidas cautelares urgentes que permiten interactuar directamente con los gobiernos ante una amenaza verosímil de violación a los derechos humanos de una persona concreta. El procedimiento para activar estos mecanismos, dado su carácter urgente, es muy flexible: se envía una carta por cualquier medio a 
los gobiernos involucrados, solicitando información y comentarios respecto a la comunicación recibida, así como acciones preventivas o de investigación realizadas.

El Procedimiento de la Resolución no 1503 (XLVIII) del ECOSOC, que fue instaurado en 1970, consiste en un mecanismo permanente y confidencial (a diferencia del procedimiento 1235 que se sustenta en mandatos temporales y es público) de recepción y tramitación de quejas individuales por violaciones de derechos humanos en un Estado determinado (en este procedimiento no caben mandatos temáticos). Ahora bien, esas quejas no se atienden de manera individualizada, pues, para su admisibilidad, es necesario que el Consejo, a partir de ellas, concluya una situación de violación manifiesta de derechos humanos. En caso de hacerlo, decidirá si tal situación merece la realización de un estudio de fondo, o una investigación a cargo de un comité especial, en cuyo caso solicitará el consentimiento del Estado en cuestión. Las conclusiones tampoco van vinculadas a la situación concreta de las personas, sino a la promoción general de los derechos humanos en el Estado de que se trate. Si bien el procedimiento es confidencial, desde 1978 se dan a conocer los Estados que han sido investigados.

Una observación final resulta necesaria. En el ámbito de NNUU no existen -a lo menos de momento- procedimientos contenciosos en materia de derechos humanos semejantes a los del Tribunal Europeo de Derechos Humanos o a los de la Corte Interamericana de Derechos Humanos. Sin perjuicio de que, en el ejercicio de sus competencias, la Corte Internacional de Justicia (CIJ) y otros Tribunales Penales Internacionales ad hoc interpretan en muchas ocasiones cuestiones de derechos humanos. También sin perjuicio de que algunos tratados internacionales sobre derechos humanos atribuyen su interpretación a la CIJ (por ejemplo, la Convención sobre la eliminación de todas las formas de discriminación contra la mujer, véase artículo 2913).

\subsection{La protección de la igualdad dentro del sistema de tratados de derechos humanos de naciones unidas}

El sistema universal convencional está conformado por nueve convenciones, conocidas como las Convenciones Centrales (Core Treaties), y sus Protocolos Facultativos. En cuanto a las garantías de efectividad de sus disposiciones, las Convenciones y sus Protocolos Facultativos han creado nueve comités y un subcomité, y establecido los procedimientos de actuación para la protección de derechos humanos.

Aunque cada tratado es distinto e independiente, la totalidad de los tratados de derechos humanos se complementan entre sí y tienen en común los principios fundamentales de la no discriminación y la igualdad, la protección efectiva contra las violaciones, la protección especial para los grupos más vulnerables y una interpretación del ser humano

\footnotetext{
${ }^{13}$ Toda controversia que surja entre dos o más Estados Partes con respecto a la interpretación o aplicación de la CEDAW que no se solucione mediante negociaciones se someterá al arbitraje a petición de uno de ellos. Si en el plazo de seis meses contados a partir de la fecha de presentación de solicitud de arbitraje las partes no consiguen ponerse de acuerdo sobre la forma del mismo, cualquiera de las partes podrá someter la controversia a la CIJ, mediante una solicitud presentada de conformidad con el Estatuto de la Corte.
} 
como participante activo en la vida pública del Estado en el que reside y en las decisiones que le afecten, y no como mero objeto pasivo de dichas decisiones.

\subsubsection{Comités con competencias de derechos humanos}

Los convenios de derechos humanos incluidos en el Sistema de Tratados de Derechos Humanos de Naciones Unidas, y los comités que crean, son los siguientes ${ }^{14}$ :

\begin{tabular}{|l|l|}
\hline \multicolumn{1}{|c|}{ Convenio } & \multicolumn{1}{|c|}{ Comité que crea } \\
\hline $\begin{array}{l}\text { Convención Internacional sobre la Eliminación de todas } \\
\text { las Formas de Discriminación Racial (1965) }\end{array}$ & $\begin{array}{l}\text { Comité para la Eliminación de la Discriminación Racial } \\
\text { (CERD) }\end{array}$ \\
\hline $\begin{array}{l}\text { Pacto Internacional de Derechos Civiles y Políticos } \\
(1966) \text {, y su Protocolo Facultativo (1966) }\end{array}$ & Comité de Derechos Humanos (CDH) \\
\hline $\begin{array}{l}\text { Pacto Internacionales de los Derechos Económicos, } \\
\text { Sociales y Culturales (1966) }\end{array}$ & $\begin{array}{l}\text { Comité de Derechos Económicos, Sociales y Culturales } \\
\text { (CDESC) }\end{array}$ \\
\hline $\begin{array}{l}\text { Convención sobre la Eliminación de todas las Formas de } \\
\text { Discriminación contra la Mujer (1979) }\end{array}$ & $\begin{array}{l}\text { Comité para la Eliminación de la Discriminación contra } \\
\text { la Mujer (CEDAW) }\end{array}$ \\
\hline $\begin{array}{l}\text { Convención contra la Tortura y otros Tratos o Penas } \\
\text { Crueles, Inhumanos o Degradantes (1984) }\end{array}$ & Comité contra la Tortura (CAT) \\
\hline Convención de los Derechos del Niño (1989) & Comité de los Derechos del Niño (CRC) \\
\hline $\begin{array}{l}\text { Convención internacional sobre la Protección de los } \\
\text { Derechos de todos los Trabajadores Migratorios y de sus } \\
\text { Familiares (1990) }\end{array}$ & $\begin{array}{l}\text { Comité de Protección de los Derechos de todos los traba- } \\
\text { jadores migrantes y sus Familiares (CMW) }\end{array}$ \\
\hline $\begin{array}{l}\text { Protocolo Facultativo a la Convención contra la Tortura y } \\
\text { otros Tratos o Penas Crueles, Inhumanos o Degradantes } \\
\text { (2002) }\end{array}$ & $\begin{array}{l}\text { Subcomité para la prevención de la tortura y otros tratos } \\
\text { o penas crueles, inhumanos o degradantes }\end{array}$ \\
\hline $\begin{array}{l}\text { Convención sobre los Derechos de las Personas con Dis- } \\
\text { capacidad (2006), y su Protocolo Facultativo (2006) }\end{array}$ & $\begin{array}{l}\text { Comité de los derechos de las personas con discapacidad } \\
\text { (CRPD) }\end{array}$ \\
\hline $\begin{array}{l}\text { Convención Internacional para la Protección de Todas las } \\
\text { Personas contra las Desapariciones Forzadas (2006) }\end{array}$ & Comité contra las Desapariciones Forzadas (CED) \\
\hline
\end{tabular}

Son características generales de los comités de derechos humanos las siguientes:

a) Son órganos creados por un tratado internacional o en aplicación de un protocolo del mismo, de ahí que no están integrados en sentido estricto en las NNUU, aunque la ONU asume su financiación y les presta soporte administrativo y técnico.

b) Son órganos técnicos colegiados integrados por expertos designados a título individual (normalmente 18, algunos más y otros menos), que no pueden recibir instrucciones gubernamentales ni de un órgano u organización, nacional o internacional.

c) Son órganos permanentes en cuanto a su creación, que desarrollan sus trabajos en periodos de sesiones predeterminados cuya duración varía de un caso a otro.

\footnotetext{
${ }^{14}$ Cuadro de elaboración propia que el autor ha publicado en la colaboración que ha realizado en el Memento Práctico Igualdad, Ediciones Francis Lefebvre (Madrid, 2019), pág. 859.
} 
d) Su competencia se circunscribe al instrumento convencional que los crea y les sirve de soporte, con lo cual carecen de competencias generales en materia de derechos humanos o respecto de cualquier otro instrumento convencional diferente al suyo.

e) Una competencia general de todos los comités es la posibilidad de aprobar observaciones o recomendaciones generales sobre la interpretación de las disposiciones de la convención que los crea, tanto disposiciones sustantivas como de procedimiento.

La diversidad de comités, y de sus normas reguladoras, genera ciertos problemas que se han intentado resolver fomentando la homogeneización de las competencias y de los procedimientos de actuación a través de la aprobación de protocolos facultativos dirigidos a ampliar las posibilidades de actuación de cada comité en comparación con las previstas en la convención que los ha creado, para homogeneizarlo con los demás.

También se ha fomentado la coordinación de la actuación de los diversos comités de derechos humanos a través de reuniones periódicas de sus presidentes, así como conjuntas de las personas miembros. Igualmente se ha fomentado la coordinación del Sistema de Tratados con el Subsistema de Relatores Especiales y en general con el Sistema Universal de Protección de Derechos Humanos de las Naciones Unidas.

\subsubsection{Procedimientos convencionales de protección de los derechos humanos}

Los procedimientos convencionales de protección de los derechos humanos a través de los cuales cada comité ejerce sus competencias dependen de la convención que lo crea y, en su caso, del protocolo que regula el procedimiento. Ahora bien, en un análisis general, hay cuatro procedimientos estándar (informes periódicos, denuncias individuales, denuncias estatales, e investigación de oficio), y una tendencia a atribuir todos los procedimientos estándar a todos los comités (aunque todavía no se ha llegado a ello). Hoy día, los procedimientos estándar atribuidos a cada comité en función de la convención que lo crea y, en su caso, del protocolo que regula el procedimiento, son ${ }^{15}$ :

\begin{tabular}{|c|c|c|c|c|}
\hline Comité & $\begin{array}{l}\text { Informes } \\
\text { periódicos }\end{array}$ & $\begin{array}{c}\text { Denuncias } \\
\text { individuales }\end{array}$ & $\begin{array}{l}\text { Denuncias } \\
\text { Estatales }\end{array}$ & $\begin{array}{c}\text { Investigación } \\
\text { de oficio }\end{array}$ \\
\hline $\begin{array}{l}\text { Comité para la Eliminación de la Discriminación Racial } \\
\text { (CERD): }\end{array}$ & Sí & Sí & Sí & No \\
\hline Comité de Derechos Humanos (CDH) & Sí & Sí & Sí & No \\
\hline $\begin{array}{l}\text { Comité de Derechos Económicos, Sociales y Culturales } \\
\text { (CDESC) tras el Protocolo Facultativo de } 2008\end{array}$ & Sí & Sí & Sí & Sí \\
\hline $\begin{array}{l}\text { Comité para la Eliminación de la Discriminación contra } \\
\text { la Mujer (CEDAW) tras el Protocolo Facultativo de } 1999\end{array}$ & Sí & Sí & No & Sí \\
\hline
\end{tabular}

\footnotetext{
${ }^{15}$ Cuadro de elaboración propia que el autor ha publicado en la colaboración que ha realizado en el Memento Práctico Igualdad, Ediciones Francis Lefebvre (Madrid, 2019), pág. 859.
} 


\begin{tabular}{|l|c|c|c|c|}
\hline Comité & $\begin{array}{c}\text { Informes } \\
\text { periódicos }\end{array}$ & $\begin{array}{c}\text { Denuncias } \\
\text { individuales }\end{array}$ & $\begin{array}{c}\text { Denuncias } \\
\text { Estatales }\end{array}$ & $\begin{array}{c}\text { Investigación } \\
\text { de oficio }\end{array}$ \\
\hline Comité contra la Tortura (CAT) & Sí & Sí \\
\hline $\begin{array}{l}\text { Comité de los Derechos del Niño (CRC) tras el } \\
\text { Protocolo Facultativo de 2011 }\end{array}$ & Sí & Sí & Sí & No \\
\hline $\begin{array}{l}\text { Comité de Protección de los Derechos de todos los } \\
\text { trabajadores migrantes y sus Familiares (CMW) }\end{array}$ & Sí & Sí & Sí & No \\
\hline $\begin{array}{l}\text { Comité de los derechos de las personas con } \\
\text { discapacidad (CRPD) }\end{array}$ & Sí & Sí & Sí & Sí \\
\hline Comité contra las Desapariciones Forzadas (CED) & Sí & Sí & Sí & Sí \\
\hline
\end{tabular}

${ }^{1}$ El Protocolo Facultativo a la Convención contra la Tortura y otros Tratos o Penas Crueles, Inhumanos o Degradantes (2002) instaura un innovador mecanismo de protección - que difiere de todos los expuestos-: se trata de un sistema global de visitas periódicas a todos los lugares en que haya o pueda haber personas privadas de libertad basado en el doble control del Subcomité para la Prevención de la Tortura, y en los mecanismos nacionales de prevención que cada Estado parte debe establecer o designar.

Dos de esos procedimientos estándar se pueden catalogar como procedimientos de carácter no contencioso. Son: el examen de los informes que obligatoria y periódicamente deben presentar los Estados parte; y las investigaciones realizadas de oficio a Estados parte en el supuesto de violaciones masivas y sistemáticas. Estos procedimientos estándar no contenciosos son los más antiguos del sistema convencional de control, y se corresponden con el respeto absoluto del principio de la soberanía estatal que imperaba en el Derecho Internacional. Con este planteamiento solo se aceptaban los procedimientos que no implicasen ningún tipo de condena o sanción a los Estados responsables de violaciones a los derechos humanos, porque esta era una materia que pertenecía exclusivamente al ámbito interno de los Estados nacionales ${ }^{16}$.

Los otros dos procedimientos estándar se pueden catalogar como procedimientos de carácter cuasicontencioso. Son: la presentación de denuncias interestatales (aunque nunca se ha utilizado en la práctica internacional, sin duda porque los gobiernos no lo consideran como políticamente correcto en el marco de las relaciones diplomáticas tradicionales); y el procedimiento de denuncias individuales. Este último procedimiento, inicialmente desconocido en los tratados de derechos humanos dado el planteamiento clásico de excluir a las personas individuales como sujetos del Derecho Internacional, se ha generalizado merced a las recomendaciones de la Conferencia de Derechos Humanos celebrada en Viena, 1993. Actualmente, y con la excepción del Subcomité para la Prevención de la Tortura, se encuentra instaurado -cada uno con sus especialidades- en la totalidad de los comités del Sistema de Tratados de Derechos Humanos de Naciones Unidas (algunos en virtud de lo establecido en el articulado de las Convenciones y otros en virtud de lo establecido en sus Protocolos Facultativos). Con este procedimiento de denuncias individuales cristaliza la capacidad procesal internacional de los individuos para la defensa de los derechos humanos, rompiendo el monopolio de los Estados como únicos sujetos protagonistas del Derecho Internacional.

${ }^{16}$ Carlos VILLAR DURÁN, Curso de Derecho Internacional de los Derechos Humanos, Editorial Trotta (Madrid, 2006), pág. 379. 
Además de estos procedimientos estándar, los comités ostentan competencias para adoptar medidas cautelares urgentes. Hay dos ejemplos que son paradigmáticos:

- El Comité para la Eliminación de la Discriminación Racial (CERD) estableció, en 1993, un procedimiento de alerta temprana y acción urgente para la prevención de las violaciones graves en virtud del cual el CERD puede recabar información de los Estados partes y adoptar una decisión en que exprese preocupaciones concretas dirigidas al Estado de que se trate, al Consejo de Derechos Humanos, al Asesor Especial sobre la Prevención del Genocidio, al Alto Comisionado para los Derechos Humanos y al Secretario General, con recomendación de someter el asunto al Consejo de Seguridad.

- La Convención Internacional para la protección de todas las personas contra las desapariciones forzadas permite al Comité contra las Desapariciones Forzadas (CED) adoptar medidas urgentes consiguientes a peticiones de los allegados a una persona desaparecida o sus representantes legales, sus abogados o las personas autorizadas por ellos, así como todo aquel que tenga un interés legítimo, a fin de que se busque y localice a una persona desaparecida (artículo 30). Si las violaciones constituyen actos generalizados o sistemáticos (es decir, se trata de crímenes de lesa humanidad), el CED, tras haber solicitado al Estado parte interesado toda la información que sea pertinente, podrá llevar la cuestión, con el carácter de urgente, a la consideración de la Asamblea General de las Naciones Unidas, por mediación del Secretario General (artículo 34).

\section{La protección específica de la igualdad a través de los procedimientos de denun- cias individuales en los tratados sobre causas concretas de discriminación}

Dentro del Sistema de Tratados de Derechos Humanos de Naciones Unidas, y más en concreto dentro de los procedimientos estándar que en ellos se contemplan, nos vamos a detener a partir de este momento en los procedimientos de denuncias individuales instaurados en los tratados sobre causas concretas de discriminación: la Convención sobre la eliminación de todas las formas de discriminación racial (1965); la Convención sobre la eliminación de todas las formas de discriminación contra la mujer (1979); y la Convención sobre los derechos de las personas con discapacidad (2006).

Vamos a tomar como modelo expositivo el Protocolo Facultativo de 1999 de la Convención sobre la eliminación de todas las formas de discriminación contra la mujer, que es el que instauró en relación con los derechos en ella reconocidos el procedimiento de denuncias individuales -sin perjuicio después de realizar determinadas precisiones en relación con los procedimientos de denuncias individuales instaurados en el ámbito de la Convención sobre la eliminación de todas las formas de discriminación racial y en el ámbito de la Convención sobre los derechos de las personas con discapacidad-. 


\subsection{Procedimiento de denuncias individuales ante el CEDAW}

El Protocolo Facultativo de 1999 de la Convención sobre la eliminación de todas las formas de discriminación contra la mujer es un convenio internacional separado y complementario de la Convención dirigido a instaurar un procedimiento de denuncias individuales ante el CEDAW. Las características generales de este procedimiento -que son comunes a todos los comités en cuyos convenios o protocolos se admiten denuncias individuales y que, dicho sea desde este inicial momento, constituyen los talones de Aquiles de todos los procedimientos de denuncias individuales- son las dos siguientes:

a) Es facultativo para los Estados partes. El CEDAW no puede examinar denuncias contra un Estado parte a menos que este haya reconocido su competencia. Hay un dato positivo: el Protocolo Facultativo de 1999 es uno de los instrumentos instauradores de procedimientos individuales de denuncias más ratificados del Sistema de Tratados de Derechos Humanos de Naciones Unidas. España lo ratificó el 6/6/2001.

b) Es un procedimiento cuasicontencioso, pues su objeto es un pronunciamiento contradictorio ante el CEDAW sobre si ha habido violación de los derechos reconocidos en la Convención sobre la eliminación de todas las formas de discriminación contra la mujer. Lo que le falta para ser totalmente jurisdiccional es que el CEDAW no tienen la capacidad de hacer cumplir directamente sus decisiones (aunque como veremos si hay mecanismos de seguimiento que pueden tener efectos positivos, y en España se admite la reparación de los daños como una responsabilidad de la Administración de Justicia).

El procedimiento ante el CEDAW se inicia con la presentación de una comunicación -que es la peculiar denominación que el Protocolo le da a las denuncias individuales acaso para evitar toda evocación semántica con un proceso contencioso-.

Las comunicaciones pueden ser presentadas por personas o grupos de personas que se hallen bajo la jurisdicción del Estado Parte y que aleguen ser víctimas de una violación por ese Estado Parte de cualquiera de los derechos enunciados en la Convención de 1979, o en nombre de esas personas o grupos de personas. Cuando se presente una comunicación en nombre de personas o grupos de personas, se requerirá su consentimiento, salvo si el autor justifica actuar en su nombre sin tal consentimiento (lo que ocurriría, por ejemplo, si la víctima se encuentra incomunicada en una cárcel o ha sido objeto de una desaparición forzada). No alude el Protocolo a la necesidad de asesoramiento letrado, aunque obvias razones aconsejan que las víctimas se asesoren.

Solo se admitirán aquellas comunicaciones concernientes a un Estado que sea parte en la Convención de 1979 y que a la vez sea parte en el Protocolo Facultativo de 1999 (lo que se explica porque el Protocolo es un convenio separado de la Convención).

Las comunicaciones se presentarán por escrito y no pueden ser anónimas. No se exige una forma determinada, pero la CEDAW -como en general todos los comités- tiene 
a disposición pública formularios donde se exige especificar: la identidad de la persona comunicante y, en el caso de ser diferente, la identidad de la víctima; el Estado implicado; los hechos denunciados y las presuntas infracciones; las gestiones hechas para agotar los recursos de la jurisdicción interna; si se han seguido otros procedimientos internacionales; la autorización -o no- para la divulgación de datos personales (pues las decisiones de la CEDAW son objeto de publicación); fecha y firma; y el listado de documentos aportados en copia (no se permite aportar originales).

Presentada la comunicación, hay una fase de admisión. De entrada, el CEDAW no examinará una comunicación a menos que se hayan agotado todos los recursos de la jurisdicción interna, salvo que la tramitación de esos recursos se prolongue injustificadamente o no sea probable que su resultado sea remedio efectivo. La lógica de la norma obliga a la persona comunicante a acreditar debidamente por qué no es probable que el resultado de un recurso sea un remedio efectivo; y al Estado concernido a detallar los recursos disponibles dejados de utilizar previamente a acudir al CEDAW.

Además, el CEDAW declarará inadmisible toda comunicación que: se refiera a una cuestión que ya ha sido examinada por el comité o ya ha sido o esté siendo examinada con arreglo a otro procedimiento de examen o arreglo internacionales; sea incompatible con las disposiciones de la Convención; sea manifiestamente infundada o esté insuficientemente sustanciada; constituya un abuso de derecho; o los hechos de la comunicación hayan sucedido antes de la fecha de entrada en vigor del Protocolo para el Estado Parte, salvo que esos hechos continúen produciéndose después de esa fecha.

Tras haber recibido una comunicación y antes de llegar a una conclusión sobre sus fundamentos, en cualquier momento el CEDAW puede dirigir al Estado Parte interesado, a los fines de su examen urgente, una solicitud para que adopte las medidas provisionales necesarias para evitar posibles daños irreparables a la supuesta víctima. Esta decisión no implicará juicio alguno ni sobre la admisibilidad ni sobre el fondo.

La fase de admisión se puede resolver sin remisión al Estado Parte interesado. A menos que el CEDAW considere que una comunicación es inadmisible sin remisión al Estado Parte, y siempre que la persona o personas interesadas consientan en que se revele su identidad a dicho Estado Parte, el CEDAW pondrá en conocimiento del Estado Parte, de forma confidencial, toda comunicación que reciba. En un plazo de seis meses, ese Estado Parte presentará por escrito explicaciones o declaraciones en las que se aclare la cuestión y se indiquen las medidas correctivas que hubiere adoptado.

El CEDAW examina las comunicaciones que recibe a la luz de toda la información puesta a su disposición por personas o grupos de personas, o en su nombre, y por el Estado Parte, siempre que esa información sea transmitida a las partes interesadas. Las comunicaciones son examinadas por el CEDAW en sesiones privadas.

Tras examinar una comunicación, el CEDAW hará llegar su opinión sobre la comunicación, así como sus recomendaciones si las hay, a las partes interesadas. Estamos ante otro ejercicio de prestidigitación semántica para eludir los términos propios de un proceso contencioso. Las denuncias son comunicaciones. Pues ahora el equivalente a las sentencias se llaman opiniones que pueden contener recomendaciones. De hecho, en la prác- 
tica del CEDAW se ha sustituido la expresión opinión por la de dictamen, sin duda más acertada en todos los sentidos (tanto jurídico como simbólico).

Los tipos de recomendaciones que, en aplicación del Protocolo, ha formulado el CEDAW incluyen las siguientes: medidas dirigidas a poner fin a las violaciones de los derechos de la víctima; medidas dirigidas a la restitución, indemnización y rehabilitación de la víctima; reforma de la legislación y cambios en las prácticas constitutivas de violaciones; y medidas para prevenir la repetición de la violación.

No se contempla la posibilidad de recurrir el dictamen del CEDAW -ni de ningún comité del Sistema de Tratados de Derechos Humanos de Naciones Unidas-.

Ya hemos avanzado que lo que le falta a este procedimiento de denuncias individuales para ser totalmente jurisdiccional es que el CEDAW no tiene la capacidad de hacer cumplir directamente sus opiniones decisiones. No obstante, se establecen tres disposiciones dirigidas a atribuir eficacia jurídica a los dictámenes y recomendaciones:

- el Estado Parte dará la debida consideración a las opiniones del comité, así como a sus recomendaciones, si las hubiere (es una obligación derivada del deber de cooperación de los Estados Parte con el cumplimiento de los fines del CEDAW);

- el Estado Parte deberá enviar al CEDAW, en un plazo de 6 meses, una respuesta por escrito, especialmente con la información sobre toda medida que se haya adoptado en orden a las opiniones y recomendaciones emitidas por el CEDAW;

- el CEDAW podrá invitar al Estado Parte a presentar más información sobre cualesquiera medidas que el Estado Parte hubiera adoptado en respuesta a sus opiniones o recomendaciones, si las hubiere, incluso, si el Comité lo considera apropiado, en los informes que presente más adelante el Estado Parte de acuerdo con el artículo 18 de la Convención (donde se contempla el procedimiento estándar de informes periódicos).

Junto a este procedimiento de denuncias individuales, se contempla una posibilidad de actuación de oficio si el CEDAW recibe información fidedigna que revele violaciones graves y sistemáticas por un Estado Parte de los derechos enunciados en la Convención de 1979. Se trata de un procedimiento de oficio que el Estado Parte puede excluir en el momento de la firma, ratificación o adhesión al Protocolo de 1999.

Finalmente, se establece una garantía de indemnidad: Cada Estado Parte adoptará todas las medidas necesarias para garantizar que las personas que se hallen bajo su jurisdicción no sean objeto de malos tratos ni intimidación como consecuencia de cualquier comunicación con el CEDAW de conformidad con el Protocolo. Se trata de una garantía amplia que no solo abarca a quienes presentan la comunicación, sino en general a todas las personas que puedan ser represaliadas a consecuencia de la misma.

En conclusión, y aún a pesar de todas las limitaciones derivadas de su carácter facultativo, de no incluir competencias de ejecución de los dictámenes, y también de la regulación del procedimiento, con disposiciones muy generales en particular en orden a la admisión de la comunicación -cuya concreción queda al arbitrio del CEDAW-, y trámites que asemejan 
se cumplirán con lentitud -generando una duración que se unirá a la ya previsiblemente larga de los recursos internos que deben ser agotados antes de presentar la denuncia al CEDAW-, aún a pesar de todo ello, el Protocolo de 1999 se debe valorar positivamente. Así lo ha entendido también la doctrina científica. Se ha dicho que, a pesar de que el Protocolo Facultativo es simplemente un derecho internacional blando que depende de la presión política en lugar de la fuerza legal, su adopción marca un momento histórico pues facilitará que las mujeres que sean víctimas de una violación de la Convención presenten una queja contra sus Estados ante el Comité, de manera que la Convención se convierte en algo más que una mera declaración de principios ${ }^{17}$. Y es que al entregar a las mujeres el poder para quejarse contra la discriminación se revitaliza el marco internacional de derechos humanos ${ }^{18}$.

\subsection{Procedimiento de denuncias individuales ante el CERD}

El procedimiento de denuncias individuales seguido ante el Comité para la Eliminación de la Discriminación Racial (CERD) responde a las mismas características generales que el seguido ante la CEDAW: es facultativo (según el artículo 14 de la Convención sobre la eliminación de todas las formas de discriminación racial, los Estados Partes pueden formular una declaración aceptando la competencia del CERD); y es cuasijurisdiccional (de manera que sus decisiones sobre el fondo de una denuncia se limitan a hacer sugerencias y/o recomendaciones, sin potestad para su ejecución).

Las denuncias pueden ser presentadas no solo por particulares o en nombre de ellos, sino también por grupos de personas o en representación de tales grupos. Se establece el plazo de 6 meses para la presentación a partir de la fecha del fallo definitivo pronunciado por una autoridad nacional en el caso. El hecho de que el mismo asunto esté pendiente o haya sido objeto de una decisión con arreglo a otro procedimiento internacional no se considerará un obstáculo para la admisibilidad de la denuncia.

Una vez registrada la denuncia, el Estado Parte dispone de tres meses para presentar sus observaciones sobre la admisibilidad de la denuncia o, si no tiene ninguna objeción a este respecto, sobre el fondo. A partir de entonces caben dos posibilidades:

- Si el Estado Parte impugna la admisibilidad, el peticionario dispondrá de seis semanas para presentar sus comentarios sobre las observaciones del Estado parte; a continuación, el CERD adoptará una decisión sobre la admisibilidad; si el CERD concluye que el caso es admisible, el Estado Parte dispondrá de otros tres meses para presentar observaciones sobre el fondo; el peticionario tendrá luego seis semanas para presentar sus comentarios al CERD antes de que este adopte una decisión definitiva.

\footnotetext{
${ }^{17}$ Kwong-leung TANG, “Internationalizing Women's Struggle against Discrimination: The UN Women's Convention and the Optional Protocol", British Journal of Social Work (2004) 34, pág. 1185.

${ }^{18}$ Catharine MACKINNON, “CEDAW's Optional Protocole Procedures”, Interrights Bulletin: A Review of the International Centre for the Lgal Protection of Human Rights, vol. 14, núm. 4, 2004, pág. 174.
} 
- Si, por el contrario, el Estado Parte solo impugna la admisibilidad y solo ha presentado observaciones relativas al fondo, el peticionario dispondrá de seis semanas para presentar sus comentarios antes de que el CERD adopte una decisión definitiva.

Las decisiones sobre el fondo de una denuncia -que, como ocurre con el CEDAW, se denominan opiniones- pueden incluir sugerencias y/o recomendaciones, incluso si ha llegado a la conclusión de que no ha habido violación. Estas sugerencias o recomendaciones pueden ser generales o específicas, y estar dirigidas al Estado Parte concernido en el procedimiento de denuncia individual o a todos los Estados Partes en la Convención. Por lo tanto, las decisiones sobre el fondo de una denuncia no están sometidas a un principio estricto de congruencia, tanto objetivamente (pueden ser generales) como subjetivamente (pueden dirigirse a Estados diferentes al concernido).

\subsection{Procedimiento de denuncias individuales ante el CRPD}

El procedimiento de denuncias individuales seguido ante el Comité de los derechos de las personas con discapacidad (CRPD) está contemplado en un Protocolo facultativo que se aprobó el mismo día en que se aprobó la Convención sobre los derechos de las personas con discapacidad. Se trata de un tratado separado abierto a los Estados Partes en la Convención, y en el cual se establece la competencia del CERD.

Las denuncias se considerarán inadmisibles tanto si el mismo asunto está siendo examinado por otro procedimiento de investigación o arreglo internacional, como si ya han sido examinadas con arreglo a dicho procedimiento o también por el propio CRPD.

El CERD, aplicando los criterios establecidos en el artículo 12 de la Convención, reconoce la capacidad jurídica de la presunta víctima, independientemente de que esta capacidad la reconozca el Estado Parte contra el que se dirija la denuncia.

\section{Sobre la eficacia interna de los dictámenes del CEDAW: el caso González Carreño vs. España}

El Caso de Doña Ángela González Carreño es bien conocido, no solo por quienes operan en el mundo jurídico, también más ampliamente por la opinión pública, tanto por la importante trascendencia mediática que en su momento tuvo el asesinato de su hija a manos de su padre, y el suicidio de este, como por la no menos importante trascendencia tanto jurídica como mediática que ha tenido el Dictamen de 16 de julio de 2014 (Comunicación 47/2012) del CEDAW, según el cual España ha incumplido con las obligaciones que le corresponde asumir como Estado parte ${ }^{19}$. La trascendencia del Caso, así jurídica

${ }^{19}$ Sobre este Dictamen de 16 de julio de 2014 (Comunicación 47/2012) del CEDAW y la inicial decisión gubernati- 
como mediática, continúa merced a la Sentencia 1263/2018, de 17 de julio, de la Sala de lo Contencioso administrativo del Tribunal Supremo (Rec. Cas. 1002/2017) ${ }^{20}$, que, en contra de la inicial decisión gubernativa -confirmada por la Audiencia Nacional-, ha admitido la eficacia interna del Dictamen, a pesar de no haber un trámite previsto para ello en nuestro ordenamiento jurídico interno, a través de una responsabilidad por un anormal funcionamiento de la Administración de Justicia. Merced a esta jurisprudencia, la eficacia de los dictámenes del CEDAW no se detiene en el caso particular, y alcanza un aspecto más general a través de su eficacia doctrinal.

\subsection{Eficacia sobre el caso particular}

La especial configuración del recurso de casación en el orden contencioso administrativo facilita enormemente la fijación de los términos del debate casacional, pues es la propia Sala del Tribunal Supremo la que fija sus términos mediante un auto. En el caso, la Sala, en Auto de 5/7/2017, precisó que las cuestiones en las que la Sala entiende que existe un interés casacional objetivo para la formación de jurisprudencia son las siguientes: (1) Cuál debe ser el cauce adecuado para solicitar del Estado español el cumplimiento de los dictámenes del Comité de la CEDAW, emitidos en los términos y por el procedimiento previsto en el Protocolo Facultativo de la Convención -ratificado por España-, cuando se contienen en tales dictámenes recomendaciones dirigidas a nuestras autoridades a fin de que reparen los daños derivados del incumplimiento constatado de los derechos previstos en la Convención. (2) 0 si, como sostiene la sentencia de instancia, la inexistencia de un procedimiento en el ordenamiento español que posibilite dotar de eficacia ejecutiva a aquellas recomendaciones y la ausencia de mecanismos necesarios para la tutela eficaz de los derechos reconocidos en la Convención no permiten exigir autónomamente el cumplimiento de aquellos dictámenes, más allá de la posible revisión por los cauces correspondientes de la decisión del Estado español de denegar la reparación solicitada.

El Tribunal Supremo, en una fundamentación jurídica densa e impecable, realiza una serie de consideraciones sobre: (1) el carácter vinculante / obligatorio para el Estado parte de los Dictámenes del Comité de la CEDAW según lo establecido en la Convención -artículo 24- y en el Protocolo -artículo 7.4-, y ello aún reconociendo que ni la Convención ni el Protocolo instauran una instancia superior supranacional, ni el carácter ejecutivo de dichos Dictámenes; (2) la integración en nuestro ordenamiento jurídico del Convenio y el Protocolo, según la Constitución Española -artículo 96-, siendo además criterio interpretativo

\footnotetext{
va de no darle eficacia interna por no haber trámite previsto para ello en nuestro ordenamiento jurídico interno, José Fernando LOUSADA AROCHENA, "El Caso González Carreño contra España”, Aequalitas: Revista jurídica de igualdad de oportunidades entre mujeres y hombres, núm. 37, 2015.

${ }^{20}$ Sobre esta Sentencia del Tribunal Supremo que finalmente sí le dio eficacia interna al Dictamen del CEDAW: José Fernando LOUSADA AROCHENA, "Las consecuencias del Caso González Carreño contra España (a propósito de la STS, Contencioso, de 17 de julio de 2018)”, Igualdad: Revista Jurídica de Igualdad de la Asociación de Jueces Francisco de Vitoria, núm. 1, 2018; y Cesáreo GUTIÉRREZ ESPADA, "La aplicación en España de los Dictámenes de Comités Internacionales: La STS 1263/2018, un importante punto de inflexión”, Cuadernos de Derecho Transnacional, vol. 10, núm. 2, Octubre 2018.
} 
de las normas relativas a los derechos fundamentales -artículo 10.2-; (3) en consecuencia, la no adopción por España de medidas reparadoras del derecho a la no discriminación vulnerado según el Dictamen de la CEDAW representan el mantenimiento de la lesión en los términos de los artículos 14 y 24 de la Constitución Española; y (4) la responsabilidad patrimonial del Estado es el remedio efectivo último para la reparación del derecho, no tanto por estar vinculada al fatal desenlace que ciertamente acaeció hace años, cuanto por no haber sido restaurada la lesión de derechos por el Estado tras el Dictamen del Comité del CEDAW.

A la vista de todo lo anterior, se sienta la siguiente doctrina general: (1) la inexistencia de un cauce específico y autónomo para hacer efectivas en el ordenamiento español las recomendaciones de un Dictamen del Comité de la CEDAW por vulneración de derechos fundamentales reconocidos en la Convención por parte del Estado español, impide exigir autónomamente el cumplimiento de aquellos dictámenes; y (2) no obstante esa afirmación, dado que la existencia de un cauce adecuado y eficaz para hacer valer el reconocimiento de la vulneración de derechos fundamentales ante los órganos judiciales españoles atañe directamente al respeto y observancia por los poderes públicos españoles de los derechos fundamentales, es posible admitir en este caso que ese Dictamen sea el presupuesto habilitante para formular una reclamación de responsabilidad patrimonial del Estado por funcionamiento anormal de la Administración de Justicia como último cauce para obtener la reparación, ello con independencia de la decisión que resulte procedente en cada caso e, incluso, de la posible procedencia de otros en los supuestos de hecho que puedan llegar a plantearse.

Doctrina general que, aplicada al caso, le permite al Tribunal Supremo concluir que la Administración vulneró derechos fundamentales de la recurrente, concretamente sus derechos a la igualdad y a no ser discriminada por razón de sexo, a la integridad física y moral, y a la tutela judicial efectiva, y ello por no asumir la demanda de reclamación de responsabilidad patrimonial y poner fin a los efectos de una declaración de lesión de derechos de la mujer por haber sufrido un acto de discriminación derivado de una situación de violencia sobre la mujer, que le vinculaba en los términos de la Convención y el Protocolo Facultativo. Finalmente, ello conduce a casar y anular la sentencia impugnada, así como la inicial decisión administrativa por silencio, y declarar la obligación de la Administración de reparar esa vulneración imponiéndole directamente una condena por importe de $600.000 €$ por los daños morales padecidos.

Considerando los argumentos usados en esta Sentencia del TS, las conclusiones alcanzadas para el CEDAW resultan extensibles mutatis mutandis a otros comités integrados en el Sistema de Tratados de Derechos Humanos de Naciones Unidas cuya competencia haya sido reconocida a través de las oportunas ratificaciones por España.

\subsection{Eficacia doctrinal}

Hay otra consecuencia derivada de la eficacia interna de los Dictámenes el CEDAW en la que conviene detenerse, y es dar entrada en el ordenamiento interno a los criterios 
jurisprudenciales del CEDAW. Se trata de una consecuencia de notable importancia pues el CEDAW ha superado el concepto tradicional de discriminación vinculado a las diferencias de trato entre situaciones de hecho comparables, para asumir un concepto moderno de discriminación vinculado a las diferencias de estado generadoras de desigualdades de oportunidades derivadas de los prejuicios asociados al sexo que colocan a las mujeres en subordinación frente a la posición de los hombres; de ahí que nuestra mejor doctrina científica nos hable de subordiscriminación ${ }^{21}$. De hecho, el Dictamen del Caso González Carreño vs. España se inscribe en una línea doctrinal del CEDAW, perfectamente identificable dentro su jurisprudencia, que avala el enjuiciamiento con una perspectiva de género y que ha cristalizado en la Recomendación General 33 del CEDAW sobre el acceso de las mujeres a la Justicia (2015), en particular en el epígrafe "los estereotipos y los prejuicios de género en

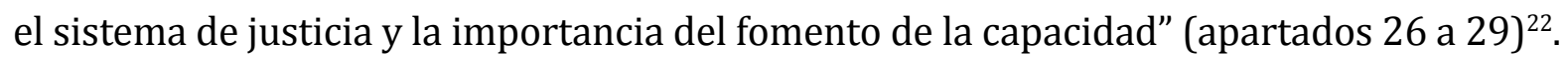

Y todo esto se aprecia en los razonamientos más significativos que, después del examen de los hechos, el Comité de la CEDAW alcanza en el Caso González Carreño: "todos estos elementos reflejan un patrón de actuación que obedece a una concepción estereotipada del derecho de visita basado en la igualdad formal que, en el presente caso, otorgó claras ventajas al padre a pesar de su conducta abusiva y minimizó la situación de madre e hija como víctimas de violencia, colocándoles en una situación de vulnerabilidad"; "en asuntos relativos a la custodia de los hijos y los derechos de visita el interés superior del niño debe ser una consideración esencial, y ... cuando las autoridades nacionales adoptan decisiones al respecto deben tomar en cuenta la existencia de un contexto de violencia doméstica"; "los estereotipos afectan el derecho de la mujer a un proceso judicial imparcial"; "la judicatura no debe aplicar estándares inflexibles sobre la base de nociones preconcebidas sobre lo que constituye violencia doméstica"; "las autoridades del Estado, al decidir el establecimiento de un régimen de visitas no vigilado aplicaron nociones estereotipadas $\mathrm{y}$, por lo tanto, discriminatorias en un contexto de violencia doméstica, y fallaron en su obligación de la debida vigilancia".

Tal concepto moderno de discriminación sistémica basado en la existencia de estereotipos de género generadores de diferencias de oportunidades y no solo en diferencias puntuales de trato entre mujeres y hombres ya se encuentra asumido en el derecho español a través de la Ley Orgánica 1/2004, de 28 de diciembre, de Medidas de Protección Integral contra la Violencia de Género (LOPIVG), y de la Ley Orgánica 3/2007, de 22 de marzo, para la Igualdad Efectiva de Mujeres y Hombres (LOIEMH).

En la LOPIVG ello se aprecia con toda claridad en la misma definición de la violencia de género en la relación de pareja que es objeto de protección: la violencia que, como manifestación de la discriminación, la situación de desigualdad y las relaciones de poder

\footnotetext{
${ }^{21}$ Termino acuñado por Maggy BARRÈRE. Véase más ampliamente: Juana María GIL RUÍZ (coord.), El Convenio de Estambul como marco de derecho antisubordiscriminatorio, Editorial Dykinson (Madrid, 2018); Asunción VENTURA FRANCH / Santiago GARCÍA CAMPÁ, El derecho a la igualdad efectiva de mujeres y hombres. Una evaluación del primer decenio de la Ley Orgánica 3/2007, Editorial Aranzadi (Pamplona, 2019); y María Ángeles (Maggy) BARRÈRE UNZUETA, Feminismo y Derecho (Fragmentos para un derecho antisubordiscriminatorio), Editorial Olejnik (Santiago de Chile, 2019).

${ }^{22}$ Sobre esta línea jurisprudencial del CEDAW, y su recepción en la RG 33, José Fernando LOUSADA AROCHENA, El enjuiciamiento de género, Editorial Dykinson (Madrid, 2020), págs. 100 a 109.
} 
de los hombres sobre las mujeres, se ejerce sobre estas por parte de quienes sean o hayan sido sus cónyuges o de quienes estén o hayan estado ligados a ellas por relaciones similares de afectividad, aun sin convivencia" -artículo 1.1-.

Y la LOIEMH concibe la igualdad, no solo como un valor fundamental o un principio -que es como la califica la CE, artículos 1 y 14-, también como un "derecho de igualdad de trato y oportunidades entre mujeres y hombres" -artículo 1-, con la dimensión objetiva o institucional que caracteriza a todo derecho fundamental, según la cual "la igualdad de trato y de oportunidades entre mujeres y hombres es un principio informador del ordenamiento jurídico y, como tal, se integrará y observará en la interpretación y aplicación de las normas jurídicas" -artículo 4-. Por ello, asume el principio de transversalidad, dirigido a integrar la perspectiva de género en la totalidad del ordenamiento jurídico y las políticas públicas para erradicar los estereotipos de género -artículos 14 y 15-. En suma, y como se dice en su Exposición de Motivos: "la consideración de la dimensión transversal de la igualdad, seña de identidad del moderno derecho antidiscriminatorio, (es) principio fundamental del presente texto".

La asunción por el Comité de la CEDAW de este concepto moderno de discriminación por razón de sexo / género casa a la perfección con lo que ya se establece en la LOPVIG y en la LOIEMH. Y, al haberle dado efectividad interna a los Dictámenes del Comité de la CEDAW, la Sentencia 1263/2018, de 17 de julio, de la Sala de lo Contencioso administrativo del Tribunal Supremo, refuerza esta manera de entender la discriminación con la finalidad de su detección, prevención y erradicación. Desde la perspectiva de la aplicación judicial, se podría concluir que el concepto moderno de discriminación que encontramos en la LOPIVG y en la LOIEMH hay que aplicarlo no solo porque lo digan esas leyes: también porque lo dice la Convención sobre la eliminación de todas las formas de discriminación contra la mujer (CEDAW).

Si todo esto lo proyectamos sobre los demás comités del Sistema de Tratados de Derechos Humanos de Naciones Unidas, la doctrina por ellos sentada debe ser tomada muy en consideración, de ahora en adelante, en la legislación y en la doctrina judicial cuando en el litigio esté implicado alguno de los derechos humanos reconocidos en alguno de los tratados ratificados por España -como de hecho ya debería ser así si consideramos que los tratados una vez ratificados forman parte de nuestro ordenamiento jurídico, que los comités realizan una suerte de interpretación auténtica, y que las normas relativas a los derechos fundamentales y a las libertades que nuestra Constitución reconoce se interpretarán de conformidad con la Declaración Universal de Derechos Humanos y los tratados y acuerdos internacionales sobre las mismas materias ratificados por España, según se establece en el artículo 10.2 de nuestra Constitución-. 